\title{
EXIBIÇÃO DO FILME "UMA VIAGEM EXTRAORDINÁRIA" NAS AULAS DE FÍSICA: A IMPORTÂNCIA DA INTERLIGAÇÃO ENTRE CIÊNCIA E ARTE NA EJA
}

\author{
M. R. DA SILVA ${ }^{1}$, S. R. P. DE MENDONÇA ${ }^{2}$, A. T. C. DE SOUZA \\ Instituto Brasil ${ }^{1}$, Instituto Federal de Educação, Ciência e Tecnologia do Rio Grande do Norte ${ }^{2,3}$ \\ romeniadsilva@gmail.com ${ }^{1}$
}

Submetido em 25/01/2019 e aceito em 17/02/2020

DOI: $10.15628 /$ holos. 2020.8238

\section{RESUMO}

Esse artigo discorre sobre a importância do processo de formação cultural dos alunos da EJA, por intermédio da reflexão de um filme, visto que, a linguagem cinematográfica auxilia na leitura de mundo, permitindo o estabelecimento das relações entre o saber científico e a realidade dos educandos. Compreendendo a formação cultural como o processo pelo qual o indivíduo se conecta ao mundo da cultura por meio de atividades específicas, realizamos um estudo com alunos do CEJA Professora Lia Campos que participaram de uma atividade na disciplina de Física, a qual tinha por objetivo promover o diálogo entre Ciência e Arte, a partir da exibição do filme "Uma Viagem Extraordinária". Sinalizamos que os dados da pesquisa revelaram um cenário que está em consonância com os estudos realizados na área. Vale salientar que, a maioria dos estudantes envolvidos na atividade
\end{abstract}

elencaram que as reflexões sobre Ciência e Arte provocadas através do filme foram significativas. Visando ter uma melhor compreensão da realidade dos alunos da EJA, foi aplicado um questionário seguido de uma entrevista. Os participantes foram questionados sobre como eles consideram o acesso a bens culturais, arte e literatura na região em que vivem. Com base na análise dos dados podemos perceber que a maioria julgou que os bens culturais são de fácil acesso, no entanto, afirmaram que não frequentam com regularidade esses espaços (museus, teatros, cinemas, planetários etc.). Portanto, é de fundamental importância a realização de atividades dessa natureza dentro do contexto de formação cultural do aluno da EJA, uma vez que, possibilita momentos de alfabetização científica do aluno cidadão/trabalhador.

PALAVRAS-CHAVE: Formação cultural, Ciência, Física, Cinema, EJA

\section{THE DIALOGUE BETWEEN SCIENCE AND ART IN THE EJA: EXHIBITION OF THE FILM "AN EXTRAORDINARY JOURNEY" IN PHYSICAL LESSONS}

\section{ABSTRACT}

This article discusses the importance of the process of cultural formation of the students of the EJA, through the reflection of a film, since, the cinematographic language assists in the reading of the world, allowing the establishment of the relations between the scientific knowledge and the reality of the students. Understanding cultural formation as the process by which the individual connects to the world of culture through specific activities, we carried out a study with students from JSCA Professor Lia Campos who participated in an activity in the discipline of Physics, which aimed to promote the dialogue between Science and Art, from the screening of the film "An Extraordinary Journey". We note that the research data revealed a scenario that is in line with the studies carried out in the area. It is worth noting that most of the students involved in the activity indicated
\end{abstract}

that the reflections on Science and Art provoked through the film were significant. Aiming to have a better understanding of the reality of the students of the EJA, a questionnaire followed by an interview was applied. Participants were asked how they consider access to cultural assets, art and literature in the region in which they live. Based on the analysis of the data, we can see that the majority judged that cultural assets are easily accessible, however, they stated that they do not regularly attend these spaces (museums, theaters, cinemas, planetariums, etc.). Therefore, it is of fundamental importance to carry out activities of this nature within the context of the cultural formation of the student of the EJA, since, it allows moments of scientific literacy of the student citizen / worker.

KEYWORDS: Cultural training, Science, Physics, Cinema, EJA. 


\section{INTRODUÇÃO}

O artigo apresenta uma discussão sobre a importância do processo de formação cultural dos alunos da EJA (Educação de Jovens e Adultos), visto que, a linguagem cinematográfica auxilia na leitura de mundo, permitindo o estabelecimento das relações entre o saber científico e a realidade dos educandos.

Por meio da utilização do cinema buscamos pensar a Física como cultura, tendo em vista que, esse instrumento permitirá trazer, entre outras coisas, elementos presentes na História da Ciência para a sala de aula. Portanto, a pesquisa tem por objetivo promover o diálogo entre Ciência e Arte, a partir da exibição do filme "Uma Viagem Extraordinária", com foco na formação cultural do aluno da EJA.

Dentre os objetivos específicos temos : Compreender a Física como uma "instituição social", em suas relações com a cultura; Contribuir para promover a contextualização e interdisciplinaridade no ensino da Física; Viabilizar a utilização de procedimentos que possibilitem a apreciação e leitura fílmica, permitindo uma formação mais crítica e reflexiva dos alunos; Promover momentos de discussão a partir da leitura fílmica, com o intuito de que os conceitos debatidos tornem-se significativos para os alunos; Compreender como se estruturaram as leis que regem a Termodinâmica, e que relação às máquinas de movimento perpétuo possui com o estabelecimento desses princípios.

A pesquisa foi desenvolvida no CEJA (Centro de Educação de Jovens e Adultos) - Professora Lia Campos, localizado na Av. Coronel Estevam, s/n - Dix-Sept Rosado, Natal - RN. O qual possui os níveis e modalidades de educação fundamental, médio e a Banca ${ }^{1}$. Vale salientar que, as turmas envolvidas na pesquisa foram as de nível médio.

O púbico da EJA, segundo Oliveira (1999), diferencia-se dos adolescentes e adultos estudantes. Para ela, o lugar social dos jovens e adultos que frequentam as aulas pode ser definido a partir de três campos: o fato de não serem crianças, a condição de excluídos da escola e a condição de pertencimento a um determinado grupo cultural. Sendo assim, buscando promover o diálogo entre dois campos do saber (Ciência e Arte), no contexto de formação cultural do aluno da EJA, realizamos um estudo com discentes da escola citada que participaram da exibição do filme "Uma Viagem Extraordinária" durante as aulas da disciplina de Física.

Levando em consideração a natureza do problema, optamos por desenvolvê-lo através da abordagem de pesquisa qualitativa (LUDKE e ANDRÉ, 1986; SEVERINO, 2007). O método utilizado é caracterizado como pesquisa de Campo, em que o objeto/fonte é abordado em seu meio ambiente próprio, uma vez que, procura o aprofundamento de uma realidade específica, e, é basicamente realizado por meio da observação direta das atividades do grupo estudado e de

\footnotetext{
${ }^{1}$ A Banca permanente de avaliação aplica provas e emite certificado de escolaridade às pessoas que não tiveram oportunidade de estudar na idade adequada.
} 
entrevistas com informantes para captar as explicações e interpretações que ocorrem naquela realidade (GIL, 2008; SEVERINO, 2007).

Quanto aos objetivos a pesquisa é de caráter exploratório e os instrumentos utilizados no trabalho de campo para coleta de dados foram questionários e entrevistas realizadas com os alunos. Segundo Lüdke \& André (1986, p.34) essas entrevistas "se desenvolvem a partir de um esquema básico, porém não aplicado rigidamente, permitindo que o entrevistador faça as necessárias adaptações". A situação de entrevista apresenta uma oportunidade para a verificação da validade das descrições. O entrevistador pode observar não apenas o que diz o entrevistado, mas também como o diz.

Compreendendo a formação cultural como o processo pelo qual o indivíduo se conecta ao mundo da cultura, mundo esse entendido como um espaço de diferentes leituras e interpretações do real, concretizado nas Artes (música, teatro, dança, Artes visuais, Cinema, entre outros) e na literatura (NOGUEIRA, 2008). Torna-se evidente a necessidade de a escola assumir essa função de oportunizar momentos de formação cultural aos educandos. Pois, é de fundamental importância a realização de atividades dessa natureza dentro do contexto de formação aluno da EJA, uma vez que, possibilita momentos que alfabetização científica do aluno cidadão/trabalhador (AUGUSTINHO, VIANA, ROÇAS, 2011).

\section{CIÊNCIA E ARTE NA EJA}

Buscando traçar o diálogo entre Ciência e Arte na sala de aula por meio da utilização do Cinema, torna-se pertinente a apresentação de dois conceitos envolvidos nesse processo de formação do aluno - a cultura e a Arte.

O conceito de Cultura é polissêmico e etimologicamente origina-se do latim (cultur), cujo significado é cultivo dedicado ao campo, às plantas e animais. Consagrou-se pelo seu uso metafórico: cultiva-se o espírito, assim como se cultiva a terra (CUCHE, 1999 apud SUANNO, 2009). O conceito de Cultura utilizado por Nelson Werneck (ZENETIC, 1989, p.97), diz que,

\footnotetext{
Cultura - Conjunto dos valores materiais e espirituais criados pela humanidade, no curso de sua história. A cultura é um fenômeno social que representa o nível alcançado pela sociedade em determinada etapa histórica: progresso, técnica, experiência de produção e de trabalho, instrução, educação, ciência, literatura, Arte e instituições que lhes correspondem. Em um sentido mais restrito, compreende-se, sob o termo de cultura, o conjunto de formas da vida espiritual da sociedade, que nascem e se desenvolvem à base do modo de produção dos bens materiais historicamente determinado. Assim, entendese por cultura o nível de desenvolvimento alcançado pela sociedade na instrução, na ciência, na literatura, na Arte, na filosofia, na moral, etc., e as instituições correspondentes. Entre os índices mais importantes no nível cultural, em determinada etapa histórica, é preciso notar o grau de utilização dos aperfeiçoamentos técnicos e dos desenvolvimentos científicos na produção social, o nível cultural e técnico dos produtores dos bens materiais, assim como o grau de difusão da instrução, da literatura e das Artes entre a população.
}

Segundo Nogueira (2009), a Arte é entendida como forma de conhecimento humano, como meio pelo qual a humanidade tem tentado compreender a realidade. Nessa perspectiva Nogueira (2009) afirma que, 
A Arte é, portanto, uma forma de interpretação do real, nem superior, nem inferior às demais: é apenas mais uma. É também múltipla, pois varia de acordo com suas diferentes modalidades ou linguagens: música, Artes visuais, teatro, dança, Cinema, fotografia, entre outras. (NOGUEIRA, 2009, p.2, grifo nosso).

De acordo com Piassi (2013), a aproximação entre Ciência e Arte na educação, proposta há tempos por Zanetic (2006) por meio da literatura, se faz também pelo uso de outras linguagens artísticas de caráter ficcional nos mais variados. Segundo Piassi (2013),

\begin{abstract}
A ciência, sendo uma prática sociocultural situada historicamente, está presente no discurso de inúmeras obras, literárias ou não, didáticas ou não, que em todo caso instituem significados em relação à interpretação que a ciência dá aos fenômenos que são objeto de seu estudo e à natureza da própria ciência como prática social. Trata-se de uma produção que desempenha papel central na difusão social dos conhecimentos científicos e na própria produção do conhecimento científico em si. (PIASSI, 2013, p. 14).
\end{abstract}

Sendo assim, também a Poesia e a Arte, parecem constituir necessidades urgentes de afirmação da experiência individual, e representam uma visão complementar e indispensável da experiência humana, não podendo ficar de fora das atividades interdisciplinares com os jovens nas escolas, mesmo aquelas ligadas ao aprendizado de Ciências. (MOREIRA, 2002, p. 18 apud PIASSI, 2013, p.15).

Os filmes constituem uma fonte riquíssima de conhecimento (DUARTE, 2002), e o uso do Cinema na sala de aula poderá proporcionar mudanças no contexto escolar, que na maioria das vezes é marcado por falta de interesse, principalmente em relação às disciplinas da área de Ciências da Natureza.

Para Napolitano,

trabalhar com o Cinema em sala de aula é ajudar a escola reencontrar a cultura ao mesmo tempo cotidiana e elevada, pois o Cinema é o campo no qual a estética, o lazer, a ideologia e os valores sociais mais amplos são sintetizados numa mesma obra de Arte (NAPOLITANO, 2013, p.11).

Assim sendo, com o objetivo de pensar a física como cultura, compartilhamos das ideias de alguns pesquisadores da área, como Zanetic (1990), Candoti (2009), Martins (2009), entre outros, os quais consideram que:

Física é cultura, dela se alimenta e com ela estabelece o diálogo necessário para formular juízos de valor sobre os fatos que envolvem a ciência e a sociedade. Pertence à cultura porque se expressa em uma linguagem que encontra seus significados nas complexas teias que os clássicos da literatura e da ciência teceram ao longo dos tempos (CANDOTTI, 2009 apud MARTINS, 2009, p.17).

Deste modo, o uso do Cinema nos oferece a possibilidade de identificar e discutir algumas das conexões que a Física estabelece na complexa teia da ciência, Arte e cultura, possibilitando construir os elos de interdisciplinaridade entre o Ensino de Física e outras disciplinas do ensino médio.

Com base nas relações entre Cinema e Educação no âmbito da EJA, alinhamos nosso pensamento a Souza (2000), ao afirmar que: "[...] a EJA necessita ser pensada como um modelo pedagógico próprios a fim de criar situações pedagógicas e satisfazer necessidades de 
aprendizagem de jovens e adultos" (SOUZA, 2000, p. 31). No entanto, ao usar o Cinema na educação, não devemos partir só do viés metodológico pedagógico, mas também dos próprios conceitos científicos do Cinema, bem como, a compreensão do Cinema enquanto Arte e sua devida contribuição para formação cultural do aluno.

Vale salientar que, a educação de jovens e adultos, no Brasil, constitui-se em um tema complexo, por isso exige uma análise mais crítica e aprofundada. Prevista na Lei 9.394/96 de Diretrizes e Bases da Educação Nacional, a modalidade EJA foi inserida na Educação Básica, tendo o objetivo de contribuir para uma formação adequada da população de jovens e adultos que não tiveram acesso ou não obtiveram sucesso no Ensino Fundamental ou no Ensino Médio na faixa etária apropriada.

Portanto, a EJA no Brasil destina-se a uma população com necessidade de atendimento educacional tardio. De acordo com Augustinho, Viana e Rôças (2011), a seção V, da LDB no 9394/96 trata da Educação de Jovens e Adultos e diz que "O Poder Público viabilizará e estimulará o acesso e a permanência do trabalhador na escola, mediante ações integradas e complementares entre si".

Partindo desse pressuposto, a lei assegura não apenas a oferta das vagas, mas também a permanência destes jovens e adultos na escola. Isto implica em uma abordagem pedagógica, currículo, metodologias, processos avaliativos diferenciados daqueles que são desenvolvidos na organização do ensino dos alunos que se encontram em idade própria (AUGUSTINHO, VIANA E RÔÇAS, 2011). Sendo assim,

a utilização de novas tecnologias em sala de aula rompe com esta visão passiva do aluno, pois proporciona elementos para uma reflexão da realidade. O Cinema, portanto, reúne entretenimento, cultura e conhecimento, daí não haver necessidade de exclusão entre entretenimento e saber escolar própria (AUGUSTINHO, VIANA E RÔÇAS, 2011, p.4).

As Diretrizes Curriculares Nacionais para o Ensino Médio definida pela Resolução №02/2012 apresenta uma organização curricular dividida em quatro áreas, a saber: Linguagens; Matemática; Ciências da Natureza e Ciências Humanas. Em todas elas encontramos como proposta:

[...] o tratamento metodológico que evidencie a contextualização e a interdisciplinaridade ou outras formas de interação e articulação entre diferentes campos de saberes específico. Constitui-se como referencial legal e conceitual a indissociabilidade entre educação e prática social, considerando-se a historicidade dos conhecimentos e dos sujeitos do processo educativo, bem como entre teoria e prática no processo de ensinoaprendizagem. E conceitua-se a ciência como "conjunto de conhecimentos sistematizados, produzidos socialmente ao longo da história na busca da compreensão e transformação da natureza e da sociedade" (BRASIL, 2012 - grifo nosso).

Diante das novas perspectivas que se apresentam pelas Leis e Diretrizes, o componente curricular de Física, necessita de redirecionamentos já que "pretende-se, uma reorientação no ensino de Física praticado, de maneira que este tenha significado para o aluno e o significado possa ser percebido por este no momento em que aprende, e não em um momento posterior ao aprendizado" (BRASIL, 1999, p.230 apud FERNANDES, 2004, p.29). Assim, almeja-se que o ensino de Física: 
Contribua para a formação de uma cultura científica efetiva, que permita ao indivíduo a interpretação dos fatos, fenômenos e processos naturais, situando e dimensionando a interação do ser humano com a natureza como parte da própria natureza em transformação. Para tanto é essencial que o conhecimento físico seja explicitado como processo histórico, objeto de contínua transformação e associado às outras formas de expressão e produção humanas. É necessário também que essa cultura em Física inclua a compreensão do conjunto de equipamentos e procedimentos, técnicos ou tecnológicos, do cotidiano doméstico, social e profissional (BRASIL, 1999, p. 229 apud FERNANDES, 2004, p.29- grifo nosso).

Nota-se, assim, que a abordagem histórica e contextualizada de fatos, fenômenos e processos naturais se torna imprescindível para o ensino de Física, em especial, para o estudo das Leis da Termodinâmica. Nessa perspectiva, a inserção dos filmes nas aulas, visa contribuir para promover a contextualização e interdisciplinaridade no ensino da Física e viabilizar a utilização de procedimentos que possibilitem a apreciação e leitura fílmica, permitindo uma formação mais crítica e reflexiva dos alunos, no processo de formação cultural.

\section{A UTILIZAÇÃO DO FILME “UMA VIAGEM EXTRAORDINÁRIA" NAS AULAS DE FÍSICA}

De acordo com Silva (2015), encontramos na literatura algumas experiências ligadas ao ensino e a aprendizagem de Física e Cinema em autores como Ferreira et al. (2010), Braga, et al (2007), Almeida (2000), Xavier et al. (2010) e Piassi (2013; 2017), tanto no âmbito de atividades direcionadas aos estudantes do ensino médio, quanto às destinadas ao processo de formação dos professores. Outros autores como Fantin (2006) e Alves Ferreira (2010) consideram ambas as perspectivas inseridas no que compreendem ser mecanismo de Formação Cultural. Tal preocupação também é apresentada por Ferreira (2010):

[...] ]o uso da sétima arte no ensino de física é uma das questões que se põe no panorama de formação do conhecimento cientifico. Destaca-se, assim, que sua aplicação na formação física permite não somente que o professor desenvolva novas metodologias em sala de aula, mas, também, que perceba, como sujeito ativo, o papel que a expressão artística tem no desencadeamento de questões. (FERREIRA et al. 2010, p.1).

Nesse sentido, com base no que foi exposto, o cinema é uma manifestação cultural extremamente eficaz e pode ser utilizado como um gerador de debates, permitindo a emergência de reflexões em sala de aula. Nesse caso, "no âmbito da Física, a discussão das películas pode corroborar ou refutar o conhecimento prévio trazido pelos estudantes, tornado mais significativa a aprendizagem" (PIASSI, 2017, p.30).

A atividade descrita no artigo se baseou no objetivo de promover o diálogo entre Ciência e Arte, a partir da exibição do filme "Uma viagem extraordinária". O filme relata em sua narrativa a criação de uma máquina de movimento perpétuo, tal como o filme Kenoma (1998), no entanto a abordagem dada pelo diretor se revela em uma perspectiva diferente. O filme nos mostra uma 
visão mais poética do elemento histórico (máquina de movimento perpétuo), retratado no filme. Trazendo a imaginação como algo imprescindível ao desenvolvimento científico.

Sendo assim, é um filme extremamente pertinente para ser discutido no contexto de Formação Cultural dos alunos da EJA, pois traz no seu enredo aspectos de História da Ciência, Filosofia, Sociologia, Cultura, Arte e Ciência. Oportunizando momentos de reflexão e discussão em torno do papel cultural e educacional do Cinema nesse processo de formação.

\subsection{Metodologia utilizada na exibição do filme}

A metodologia utilizada na exibição do filme esteve pautada nos três momentos propostos por Silva (2015, p. 250-251.): Cena 1: Sensibilização; Cena 2: Exibição; Cena 3: Reflexão.

Iniciamos a atividade com um momento de conscientização dos alunos sobre a importância da atividade realizada, a relevância da utilização do cinema, seu potencial didático e seu aspecto de linguagem educativa, bem como uma breve descrição do filme que seria utilizado. Em seguida realizamos a exibição do filme na sua íntegra, para que os alunos pudessem compreender melhor a mensagem fílmica no desencadear da obra.

Sabendo que os filmes nos oferecem um leque de possibilidades para discussão, finalizamos a atividade com o momento da reflexão, visto que, tal como ressalta Silva (2015), o filme, assim como qualquer objeto cultural, deve ser problematizado, e a reflexão consistiu em um debate direcionado por fragmentos do filme que foram distribuídos entre os alunos. Esse momento teve como foco o debate entre os conteúdos que dialogavam com a Física, bem como, as múltiplas relações interdisciplinares suscitadas a partir da leitura da obra

\section{RESULTADOS E DISCUSSÕES}

Descrevemos nessa seção os resultados obtidos no questionário pós-filme, bem como os dados da pesquisa exploratória. Durante o processo de coleta de dados foi realizada uma entrevista estruturada com o objetivo de fazer uma sondagem sobre a formação cultural do aluno da EJA, bem como, outros dados pertinentes para o desenvolvimento do trabalho. Em conjunto, fizemos a aplicação de um questionário sobre o filme "Uma viagem extraordinária".

\subsection{Questionário pós-filme}

Apresentamos nessa seção a análise do questionário aplicado após a exibição do filme, contendo questões relacionadas ao Cinema no cotidiano dos alunos e ao Cinema na escola. É importante ressaltar que, a maioria das questões foram organizadas seguindo o padrão da Escalar Likert $^{2}$. Nossa amostragem no questionário pós-filme foi composta por 24 alunos (que aceitaram

\footnotetext{
${ }^{2}$ Este tipo de escala está baseado no princípio de que a atitude geral do entrevistado remete às crenças sobre o objeto a ser investigado, assim a questão é constituída por afirmações relacionadas com o objeto pesquisado, ou seja, são afirmações assertivas sobre o assunto.
} 
participar da pesquisa) das turmas nas quais o filme foi exibido. Vale ressaltar que, nas três turmas, devido a evasão, tínhamos em média uma frequência de 10 a 15 alunos por aula.

Analisamos algumas questões com o objetivo de dialogar com o referencial teórico descrito no artigo. Ao serem questionados sobre com que frequência visitavam salas de cinema fora do circuito comercial tivemos $67 \%$ dos alunos afirmando que não tem o habito que participar de momentos de exibição de filmes fora desse contexto comercial. O gráfico a seguir mostra a distribuição das respostas.

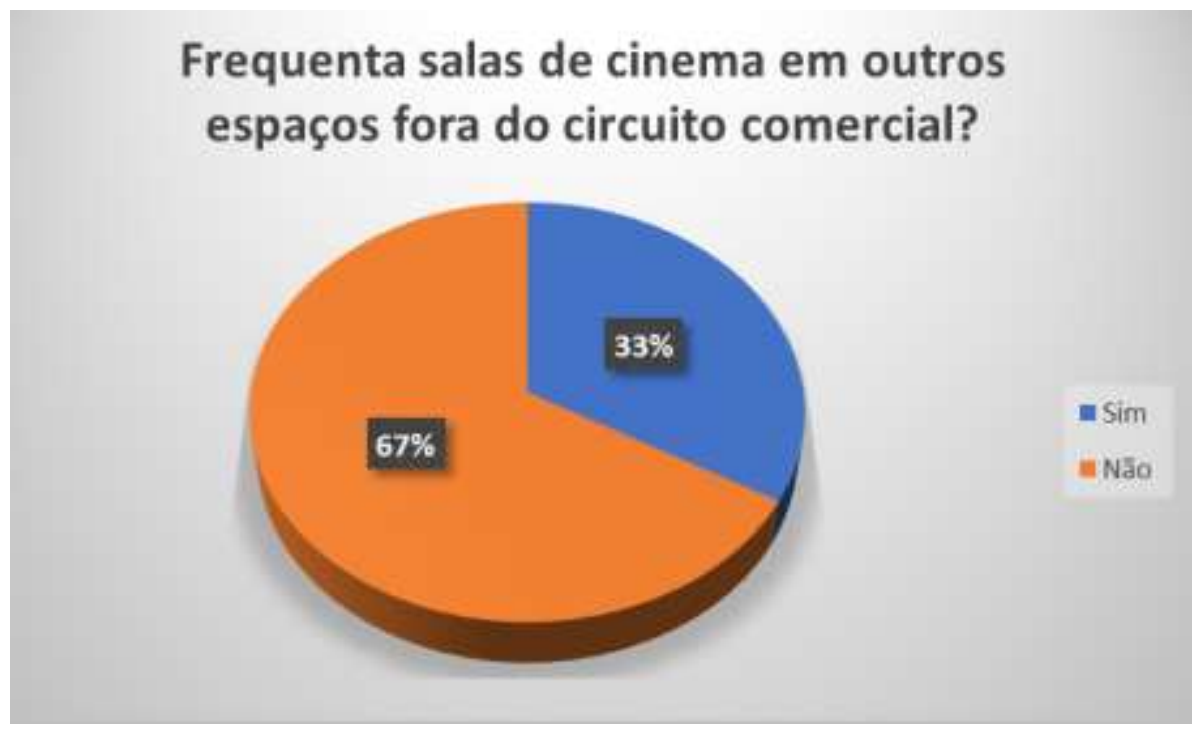

Gráfico 1: Com que frequência visita salas de cinema fora do circuito comercial.

No que se refere as reflexões sobre Ciência e Arte provocadas através do filme, a maioria (38\%) atribuiu que esse momento foi significativo. Assim como, a aquisição de novas informações relacionadas a várias áreas (História, Filosofia, Sociologia, Física, etc.) por meio do filme foi elencada pela maioria dos respondentes como suficiente.

Podemos observar no gráfico 2 a distribuição das respostas para questão que traz a base de nossa discussão no artigo, que é o diálogo entre ciência e arte no contexto de formação cultural do aluno da EJA. 


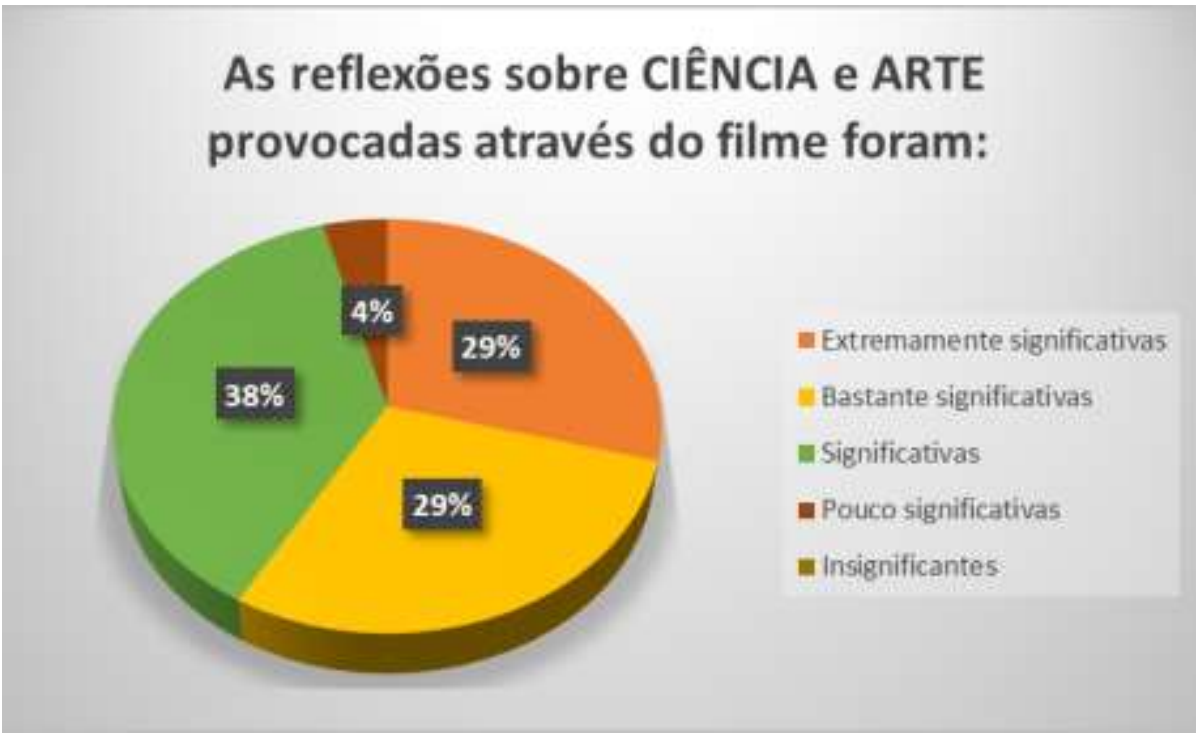

Gráfico 2: As reflexões sobre Ciência e Arte provocadas através do filme.

Dentre as demais questões de nossa pesquisa, cabe ressaltar alguns comentários deixados pelos alunos no espaço destinado a críticas e sugestões em relação ao filme exibido e a proposta da metodologia utilizada na aula de Física.

Quadro 1: Críticas e sugestões deixadas pelos alunos.

\begin{tabular}{|r|r|}
\hline ALUNO & RESPOSTAS \\
\hline Aluno A & $\begin{array}{r}\text { O filme aponta de forma representativa a teoria aprendida em sala, aspectos técnicos e } \\
\text { traz a compreensão e absorção do conhecimento. }\end{array}$ \\
\hline Aluno B & $\begin{array}{r}\text { Eu gostei muito do filme é sempre bom a gente interagir um pouco, sair da rotina de fazer } \\
\text { dever direto, eu gosto muito das aulas de Física... }\end{array}$ \\
\hline Aluno C & O filme foi bem interessante, gostei como a Física é vista em tudo. \\
\hline Aluno D & ... acho que as aulas de Física utilizando cinema contribui muito para o nosso aprendizado. \\
\hline
\end{tabular}

Portanto, finalizamos esse primeiro bloco de análise ressaltando a importância da realização de atividades dessa natureza dentro do contexto de formação do aluno da EJA, podemos perceber o envolvimento dos discente na atividade desenvolvida a partir dos relatos apresentados no quadro 1. 


\subsection{Pesquisa exploratória - Questionário 2 e entrevista}

Visando ter uma melhor compreensão da realidade dos alunos da EJA, fez-se necessário a aplicação de um questionário seguido de uma entrevista. ${ }^{3}$ Para participar do questionário 2 e da entrevista contamos com a participação de 6 alunos ( 2 alunos de cada turma que assistiu ao filme). A escolha da amostragem para a entrevista foi uma opção dos pesquisadores que tinham por objetivo fazer uma análise mais pontual e objetiva sobre a realidade dos alunos da EJA no que diz respeito a formação acadêmica, cultural e profissional.

Em relação aos sujeitos envolvidos na pesquisa, a partir de uma caracterização individual para os seis alunos pesquisados, concluímos que os sujeitos envolvidos no estudo, duas mulheres e quatro homens entre 19 e 42 anos, possuem em comum o fato de terem iniciado sua vida profissional muito cedo. Sendo assim, buscando conhecer o público da EJA e a sua necessidade de Formação para o Trabalho, questionamos os alunos sobre o que o trabalho representa em sua vida. Observamos no Gráfico a seguir, que a maioria classifica o trabalho como algo traz independência.

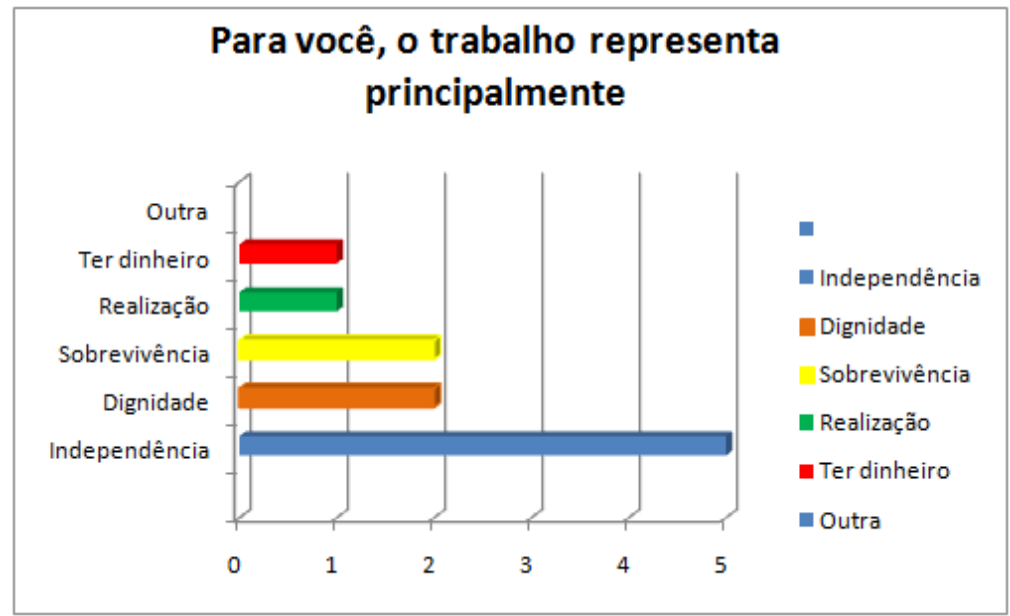

Gráfico 3: O público da EJA e a sua necessidade de Formação para o Trabalho.

Com base nos dados sinalizamos a necessidade da oferta de uma educação que possibilite uma qualificação profissional para a busca de inserção no mundo do trabalho, visto que, podemos definir o público da EJA como jovens e adultos inseridos no mundo do trabalho ${ }^{4}$ e, que, muitas vezes, já têm constituído um núcleo familiar.

\footnotetext{
${ }^{3}$ Este questionário seguido de entrevista estava inserido em uma atividade interdisciplinar como requisito de avaliação das disciplinas: CONCEPÇÕES E PRINCÍPIOS DO PROEJA; DIVERSIDADE CULTURAL E INCLUSÃO SOCIAL; PROCESSOS COGNITIVOS E CULTURAIS DA APRENDIZAGEM DOS JOVENS E ADULTOS, POLÍTICAS E LEGISLAÇÃO EDUCACIONAL DO PROEJA; GESTÃO DEMOCRÁTICA; CONCEPÇÕES CURRICULARES EM PROEJA; E DIDÁTICA EM PROEJA. DO CurSO Superior de Pós-Graduação LatoSensu em nível de Especialização, em Educação Profissional Integrada à Educação Básica na Modalidade de Educação de Jovens e Adultos - PROEJA do IFRN Campus EAD - Natal central.
}

${ }^{4}$ Segundo Figaro (2008), a categoria mundo do trabalho é ampla, complexa e envolve uma série de fatores, que se encontram inter-relacionados. Em resumo, o mundo do trabalho passa a existir a partir das relações geradas pela atividade humana do trabalho, e essas relações, simultânea e retroativamente, configuram e regulam essa atividade humana. 
Refletindo sobre a importância da formação cultural dos alunos da EJA, e compreendendo essa formação como o processo pelo qual o indivíduo se conecta ao mundo da cultura por meio de atividades específicas (NOGUEIRA, 2008), os participantes foram questionados sobre como eles consideram o acesso a bens culturais, arte e literatura na região em que vivem moram.

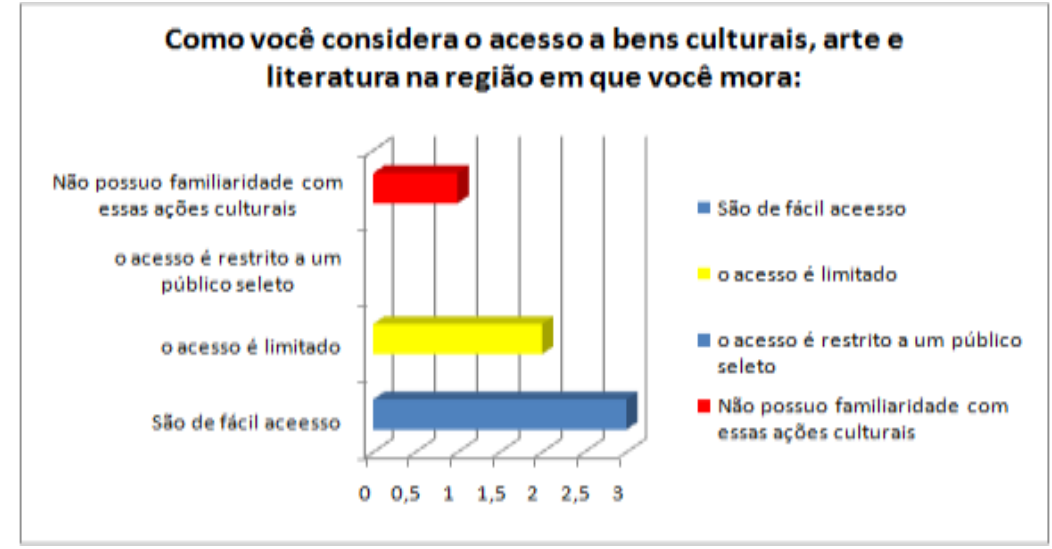

Gráfico 4 Formação cultural do aluno da EJA.

Com base no Gráfico 4 podemos perceber que a maioria julgou que os bens culturais são de fácil acesso, no entanto, afirmaram que não frequentam com regularidade esses espaços (museus, teatros, cinemas, planetários etc). Sendo assim, torna-se evidente a necessidade da escola assumir essa função de oportunizar momentos de formação cultural dos educandos. Pois, é de fundamental importância a realização de atividades dessa natureza dentro do contexto de formação aluno da EJA, uma vez que, possibilita momentos que alfabetização científica do aluno cidadão/trabalhador (AUGUSTINHO, VIANA, ROÇAS, 2011).

No que se refere à trajetória escolar dos entrevistados, apresentamos um Quadro resumo das suas respostas. Entretanto, cabe ressaltar que, apenas um aluno não relatou interrupções na sua trajetória escolar, todavia, passou por múltiplas reprovações, o que acarretou sua entrada na EJA.

Quadro 2: Quadro resumo da trajetória escolar dos entrevistados.

\begin{tabular}{|l|l|l|l|}
\hline Alunos & $\begin{array}{l}\text { Houve interrupções na } \\
\text { sua trajetória de } \\
\text { estudos? }\end{array}$ & $\begin{array}{l}\text { Quantas vezes você } \\
\text { parou e recomeçou? }\end{array}$ & $\begin{array}{l}\text { que você espera } \\
\text { conseguir a partir da } \\
\text { conclusão de seus } \\
\text { estudos? }\end{array}$ \\
\hline Aluno A & $\begin{array}{l}\text { Sim. Já concluiu o ensino } \\
\text { médio em 1996, mas } \\
\text { voltou por causa do } \\
\text { ENEM. }\end{array}$ & $\begin{array}{l}\text { Duas vezes. Entre } \\
2001 \text { e 2017. }\end{array}$ & $\begin{array}{l}\text { Continuar estudando. Fazer } \\
\text { o ENEM e tentar entrar em } \\
\text { Direito. }\end{array}$ \\
\hline Aluno B & Sim. Por 5 anos & Uma vez. & $\begin{array}{l}\text { Um futuro melhor. E fazer } \\
\text { faculdade de } \\
\text { Administração. }\end{array}$ \\
\hline Aluno C & Sim. Para trabalhar & $\begin{array}{l}\text { Duas vezes. Durante } \\
20 \text { anos. }\end{array}$ & $\begin{array}{l}\text { Conseguir um emprego e } \\
\text { fazer curso técnico na área } \\
\text { de eletricista. }\end{array}$ \\
\hline
\end{tabular}




\begin{tabular}{|l|l|l|l|}
\hline Aluno D & Sim. & $\begin{array}{l}\text { Uma vez. Começou o } \\
\text { ensino médio regular } \\
\text { e parou por 5 anos. }\end{array}$ & $\begin{array}{l}\text { Fazer o ENEM e consegui } \\
\text { um trabalho. }\end{array}$ \\
\hline Aluno E & Não. & $\begin{array}{l}\text { Nenhuma vez. Do } \\
\text { ensino fundamental } \\
\text { regular já foi direto } \\
\text { para o ensino médio } \\
\text { EJA por causa da } \\
\text { idade. }\end{array}$ & $\begin{array}{l}\text { Consegui um emprego. } \\
\text { Fazer onEM no próximo } \\
\text { faculdade de Fisioterapia. }\end{array}$ \\
\hline Aluno F & $\begin{array}{l}\text { Sim. Por causa de } \\
\text { problemas de depressão. }\end{array}$ & $\begin{array}{l}\text { Uma vez durante 3 } \\
\text { anos. }\end{array}$ & $\begin{array}{l}\text { Faz curso técnico na UFRN } \\
\text { no DEAT. Pretende fazer o } \\
\text { ENEM e cursar Artes } \\
\text { Cênicas. }\end{array}$ \\
\hline
\end{tabular}

Analisando o quadro resumo, percebemos que a maioria interrompeu sua trajetória escolar, buscando visualizar melhor o que levou essas paradas ao longo de sua formação, os alunos foram questionados sobre quais motivos contribuíram para essas interrupções. O Gráfico 5 nos traz um panorama das respostas.

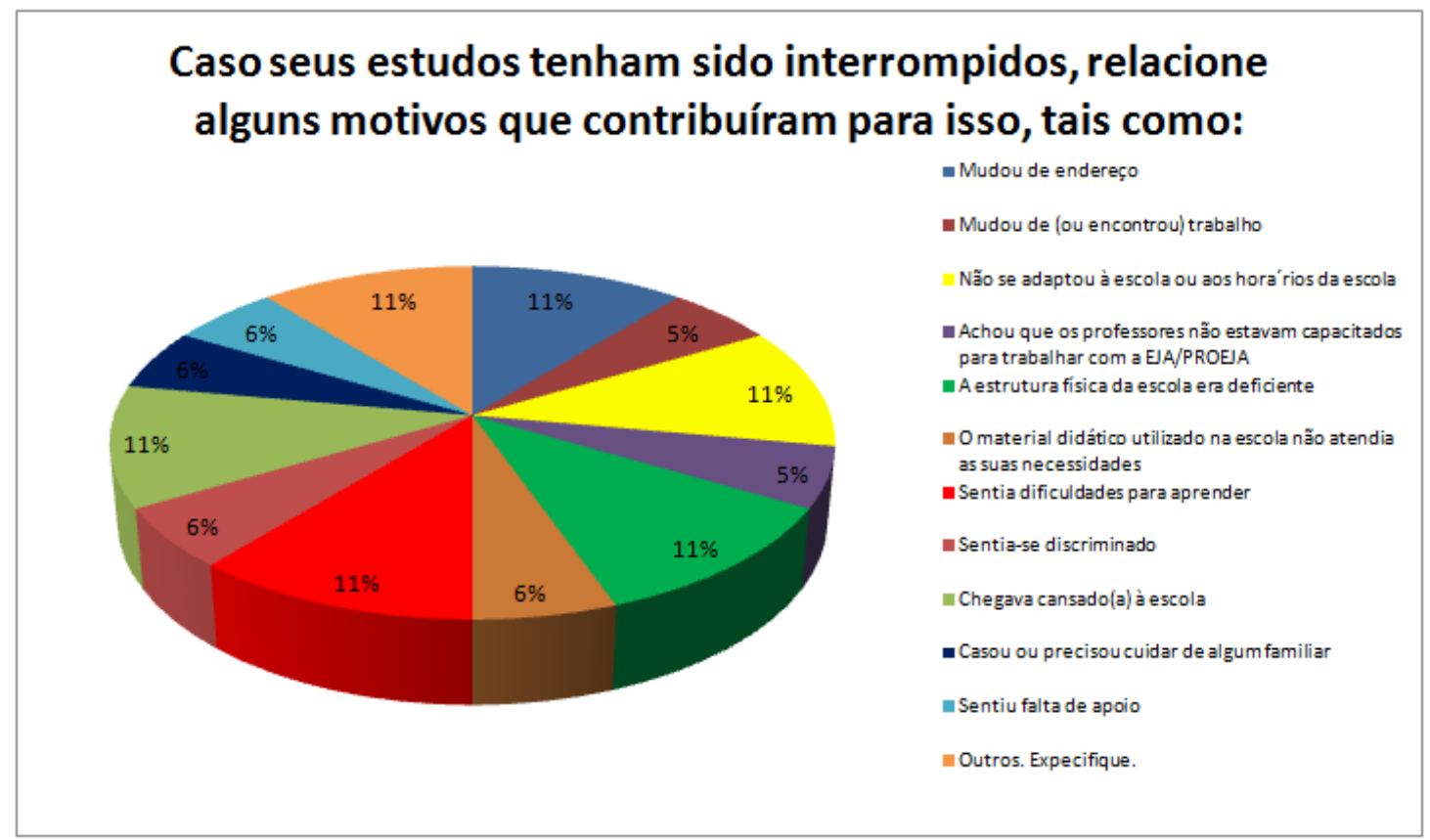

Gráfico 5: Motivos que contribuíram para a interrupção da trajetória escolar.

Analisando o gráfico, percebemos que muitos foram os motivos elencados pelos participantes, no entanto, todos voltaram à escola visando concluir seus estudos. Sendo assim, questionamos os mesmo sobre os motivos que levaram o reingresso escolar. No Gráfico a seguir observamos a distribuição das respostas. 


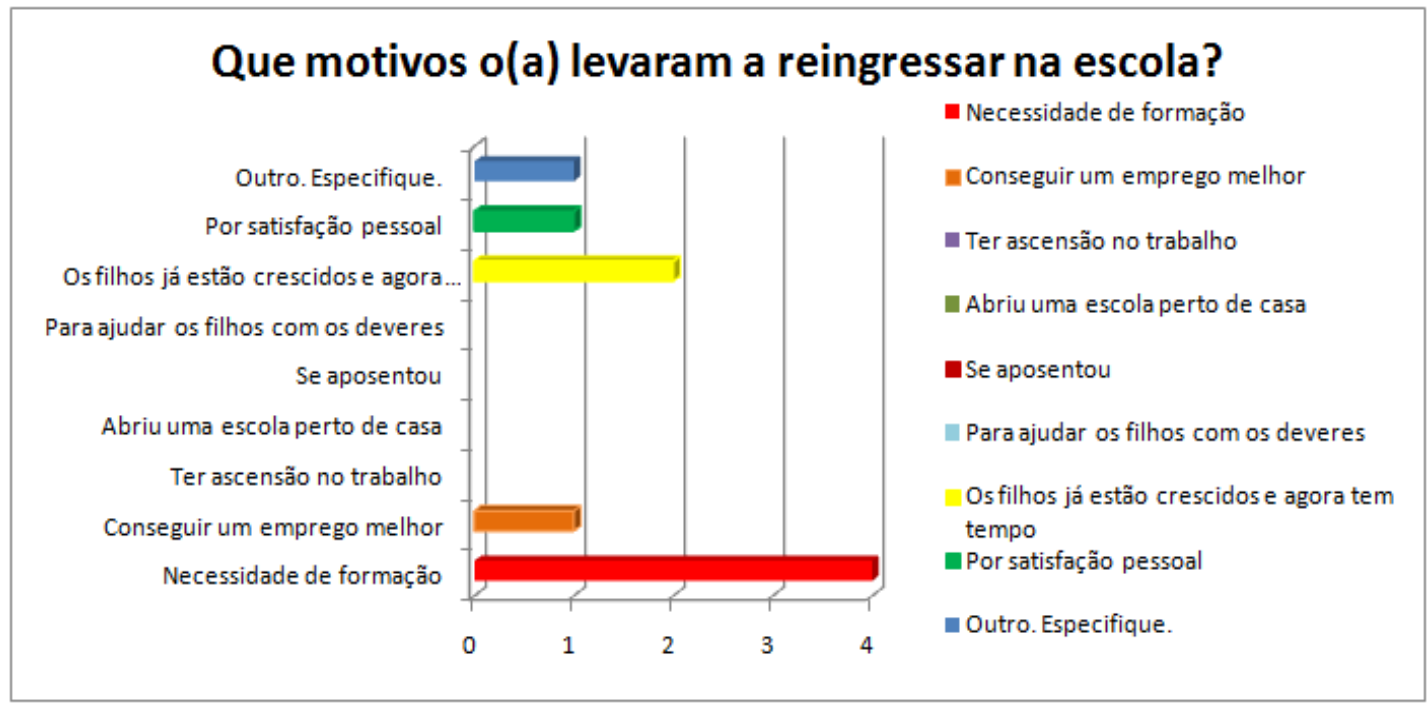

Gráfico 6: Motivos que levaram o reingresso na escola.

Portanto, a partir da análise do Gráfico 6, percebemos que a maioria sinalizou a necessidade de ter uma formação. Retomando os dados do Quadro resumo, os participantes foram questionados sobre o que esperam conseguir a partir da conclusão de seus estudos, e todos sinalizaram que pretendem continuar estudando, tentar o ingresso em uma faculdade, conseguir um emprego, dentre outras possibilidades.

\section{CONSIDERAÇÕES FINAIS}

Concluímos, ressaltando que, as características do contexto em que o educando está inserido têm forte influência na aprendizagem, perpassando os espaços socioculturais, institucionais e pessoais. Sendo assim, as atividades que visam contribuir com a formação cultural do aluno são de extrema importância no contexto acadêmico.

Ressaltamos no decorrer do artigo a importância do processo de formação cultural dos alunos da EJA, por intermédio da reflexão de um filme, visto que, a linguagem cinematográfica auxilia na leitura de mundo, permitindo o estabelecimento das relações entre o saber científico e a realidade dos educandos.

Compreendendo a formação cultural como o processo pelo qual o indivíduo se conecta ao mundo da cultura por meio de atividades específicas, realizamos um estudo com alunos do CEJA Professora Lia Campos que participaram de uma atividade na disciplina de Física, a qual tinha por objetivo promover o diálogo entre Ciência e Arte, a partir da exibição do filme "Uma Viagem Extraordinária".

Sinalizamos que os dados da pesquisa revelaram um cenário que está em consonância com os estudos realizados na área. Vale salientar que, a maioria dos estudantes envolvidos na atividade elencaram que as reflexões sobre Ciência e Arte provocadas através do filme foram significativas. Portanto, é de fundamental importância a realização de atividades dessa natureza dentro do 
contexto de formação cultural do aluno da EJA, uma vez que, possibilita momentos que alfabetização científica do aluno cidadão/trabalhador.

Nesse contexto, finalizamos ressaltando a importância da proposta para nossa formação enquanto professoras/pesquisadoras da área de ensino. São atividades dessa natureza que procuram superar a perspectiva "tradicional" de ensino e visam contribuir para a formação de um cidadão crítico e participativo, que nos motivam a continuar as pesquisas na área, em especial, estudos voltados para a formação cultural do discente da EJA.

\section{REFERÊNCIAS}

ALVES FERREIRA, Ricardo et al. Cinema e ensino de Física. In: XVIII Simpósio Nacional de Ensino de Física. Vitória, 2009.

AUGUSTINHO, Elizabeth; VIANA, Sandra da Silva; RÔÇAS, Giselle. O uso do Cinema como ferramenta pedagógica para o ensino de ciências no curso PROEJA. Disponível em: http://www.nutes.ufrj.br/abrapec/viiienpec/resumos/R1057-1.pdf, 2011. Acesso em 12/03/13.

BRASIL. Ministério da Educação - MEC, Conselho Nacional de Educação e Câmara de Educação Básica. Resolução CNE/CBE 2/2012 - Diretrizes Curriculares Nacionais para o Ensino Médio. Brasília, 2012.

BRASIL. Ministério da Educação - MEC, Secretaria de Educação Média e Tecnológica Semtec. Parâmetros Curriculares Nacionais para o Ensino Médio. Brasília: MEC/Semtec,2000.

BRAGA, Marco; GUERRA, Andreia ; REIS, José Claudio. Cinema e História da Ciência na Formação de Professores. In: XVII Simpósio Nacional de Ensino de Física, 2007, São Luís. São Paulo: SBF, v. 1, p. 1-9, 2007.

DUARTE, R. Cinema e educação. Belo Horizonte: Autêntica, 2002.

FANTIN, Monica. Produção cultural para crianças e o cinema na escola. Caxambu: 29a Reunião Anual da Anped, 2006.

FERNANDES, Simone Aparecida. O ENSINO DE FÍSICA NO NOVO ENSINO MÉDIO E OS PROCESSOS SELETIVOS PARA O ENSINO SUPERIOR. 2004. 155 f. Dissertação (Mestrado) - UFMG, Belo Horizonte.

FERREIRA, Valéria Fabiana S. et al. Cinema e Educação: Reflexões sobre uma prática pedagógica. In: IV Colóquio Internacional: Educação e Contemporaneidade. Laranjeiras, 2010.

GIL, Antonio Carlos. Como elaborar projetos de pesquisa. 4. ed. São Paulo: Atlas, 2008.

KENOMA. Brasil: Warner Bros, 1998. P\&B.

LEAL, Lucas. Cinema e/ou filme: Tecnologia e Arte na educação de jovens e adultos. Encontro FunArte políticas para as Artes. RJ/2011. 
LÜDKE, M.; ANDRÉ, M. E. D. A. de. Pesquisa em Educação: abordagens qualitativas. São Paulo: EPU, 1986.

MARTINS, André Ferrer P. Física ainda é cultura? São Paulo: Editora Livraria da Física, 2009.

MENEZES, Luís Carlos de. Uma física para o novo ensino médio. Física na Escola, São Paulo, v. 1, n. 1 , p. 6-8, out. 2000.

NAPOLITANO, Marcos. Como usar o Cinema na sala de aula, 5a edição - São Paulo: Editora Contexto, 2013.

NOGUEIRA, Monique Andries. A formação cultural de professores ou a arte da fuga. Goiânia: Editora da UFG, 2008.

NOGUEIRA, Monique Andries. Experiências estéticas em sala de aula: possibilidades na formação cultural de futuros professores. ANPED. GE-01: Educação e Arte. Disponível em: <http://www.anped.org.br/reunioes/31ra/1trabalho/GE01-4022--Int.pdf.> Acesso em 12/03/13.

OLIVEIRA, Marta Kohl de. Jovens e adultos como sujeitos de conhecimento e aprendizagem. Revista Brasileira de Educação, n 12, p. 59-73 set/out/nov/dez 1999

PIASSI, Luís Paulo de Carvalho. Interfaces didáticas entre cinema e ciência: um estudo a partir de 2001 uma odisseia no espaço. São Paulo: Editora Livraria da Física, 2013.

PIASSI, Luís Paulo. Literatura e cinema no ensino de Física: interfaces entre a ciência e a fantasia/ Luís Paulo Piassi, Emerson Ferreira Gomes, João Eduardo F. Ramos; Maurício Pietrocola, (coordenador). - 1 ed. - São Paulo: Editora Livraria da Física, 2007. - (Coleção professor inovador).

SEVERINO, Antônio Joaquim. Metodologia do Trabalho Cientifico. 23a ed. São Paulo: Cortez, 2007.

SILVA, Maria Romênia da. A linguagem audiovisual do cinema como elemento integrador da arte e ciência na formação cultural dos professores de ciências e matemática. 2015. 273f. Dissertação (Mestrado Profissional em Ensino de Ciências Naturais e Matemática) - Centro de Ciências Exatas e da Terra, Universidade Federal do Rio Grande do Norte, Natal.

SOUZA, João Francisco (Org.). A Educação de Jovens e Adultos no Brasil e no Mundo. Recife: Bagaço, 2000.

SUANNO, Marilza Vanessa Rosa. Formação Cultural de professores: conhecimento e sentipensar. IX Congresso Nacional de Educação - EDUCERE, Porto Alegre: PUCRS, 2009

UMA VIAGEM EXTRAORDINÁRIA. Direção de Jean-pierre Jeunet. França, Canadá: California Filmes, 2014. $P \& B$.

XAVIER, Carlos H. Guergel et al. $\mathbf{O}$ uso do Cinema para o ensino de física no ensino médio. Experiências em Ensino de Ciências, Mato Grosso, p. 93-106, 2010.

ZANETIC, João. Física e Arte: uma ponte entre duas culturas. Pro-Posições, v.17, n. I (49) - jan./abr. 2006.

ZANETIC, João. Física também é cultura. 1989. Tese (Doutorado em Educação) - Faculdade de Educação, Universidade de São Paulo, São Paulo. 